\title{
Pseudoatrophy of the Brain with Valproic Acid Monotherapy
}

\author{
Richard S. McLachlan
}

\begin{abstract}
A patient is described who, while on valproic acid monotherapy, developed reversible shrinkage of the brain, documented by computerized tomography with associated cognitive deficit. Although pseudoatrophy has been reported with steroid therapy, this is the first implication of an anticonvulsant drug in the etiology of that condition.

RÉSUMÉ: Pseudo-atrophie du cerveau suite à l'administration de l'acide valproïque en monothérapie. Nous décrivons le cas d'un patient qui a développé une diminution réversible du volume du cerveau associée à un déficit cognitif, documenté par tomographie assistée par ordinateur, lors d'un traitement par l'acide valproïque administré en monothérapie. Même si une pseudo-atrophie a déjà été rapportée avec l'administration de stéroïdes, le cas que nous rapportons est le premier impliquant un médicament anticonvulsivant dans l'étiologie de cette affection.
\end{abstract}

Can. J. Neurol. Sci. 1987; 14:294-296

The overall incidence of serious toxic and idiosyncratic reactions to valproic acid is low. A notable exception is the rare but often fatal hepatic encephalopathy syndrome which occurs primarily in young children. ${ }^{1.2}$ Other more common side effects such as gastrointestinal disturbances, drowsiness, weight gain, hair loss, and tremor are generally mild and reversible when the drug is discontinued. ${ }^{3.4}$ This report describes a patient on valproic acid who in addition to experiencing a number of these typical side effects, developed a reversible pseudoatrophy of the brain as documented by computerized tomography (CT).

\section{Case History}

A 17 -year-old, right-handed Grade 12 student developed seizures which began with nonspecific dizziness, followed immediately by head and eye deviation to the left, then loss of consciousness and a grand mal convulsion. There was no history of febrile convulsions, birth injury, head injury, or other serious illness. She had one brief episode of erythema nodosum at age 13 years. No family members had seizures. The neurologic examination was normal. An EEG revealed frequent right frontal spikes and delta slow waves in the same region. A CT scan was normal.

Carbamazepine, then phenytoin, each induced a rash, the latter with associated lymphadenopathy. Monotherapy with primidone, clonazepam, and phenobarbital failed to control the seizures. Valproic acid was substituted for phenobarbital and increased gradually to $2500 \mathrm{mg}$ daily in divided doses. Maximum blood level was $684 \mathrm{umol} / \mathrm{L}$ (therapeutic range 350-700 umol/L). Seizure control improved from two grand mal attacks each month to one every two months. Within two months of starting the medication, she had developed chronic nausea, mild pos- tural tremor, irregular periods, weight gain, curly hair, and most distressing to her, marked apathy and declining school performance. She had been an excellent student, but the patient, her mother and her teachers became concerned when her marks dropped by $20 \%$. She indicated that although she was not drowsy she had difficulty concentrating on her work. $\mathrm{CBC}$, serum electrolytes, proteins, renal function tests and liver function tests were normal. An ammonia level was not obtained. The EEG was unchanged (Figure 1). Reducing the dosage of valproic acid decreased her symptoms only slightly. She was not taking other medications and had no signs of systemic illness such as fever, headache, anxiety or depression.

Eight months after starting valproic acid, the CT scan was repeated and showed an enlargement of all ventricles and cisterns, and widening of cortical sulci, suggesting a diffuse atrophic process (Figure 2). These findings were best appreciated when compared with the previously normal CT scan. Valproic acid was discontinued and carbamazepine was slowly re-introduced with no ill effects. Within two weeks of stopping the valproic acid, all the patient's symptoms, which had been present for six months, disappeared and her school performance returned to its previous high level. Four months after stopping the valproic acid, the EEG continued to show right frontal abnormalities and a repeat CT scan was again normal, as was magnetic resonance imaging and neuropsychological testing. Unfortunately, the latter tests had not been done when the patient was taking valproic acid. She has been seizure free and otherwise well for more than two years.

\section{Discussion}

This patient had secondarily generalized seizures from the right frontal lobe of unknown etiology. When the diffuse abnormalities appeared on the CT scan in association with a deterioration in school performance, a degenerative brain disorder was 
considered. However, against such a process was the EEG which did not change, remaining normal in all areas except the right frontal region. These findings, plus the continuing more typical side effects of valproic acid, prompted the change in drug therapy.

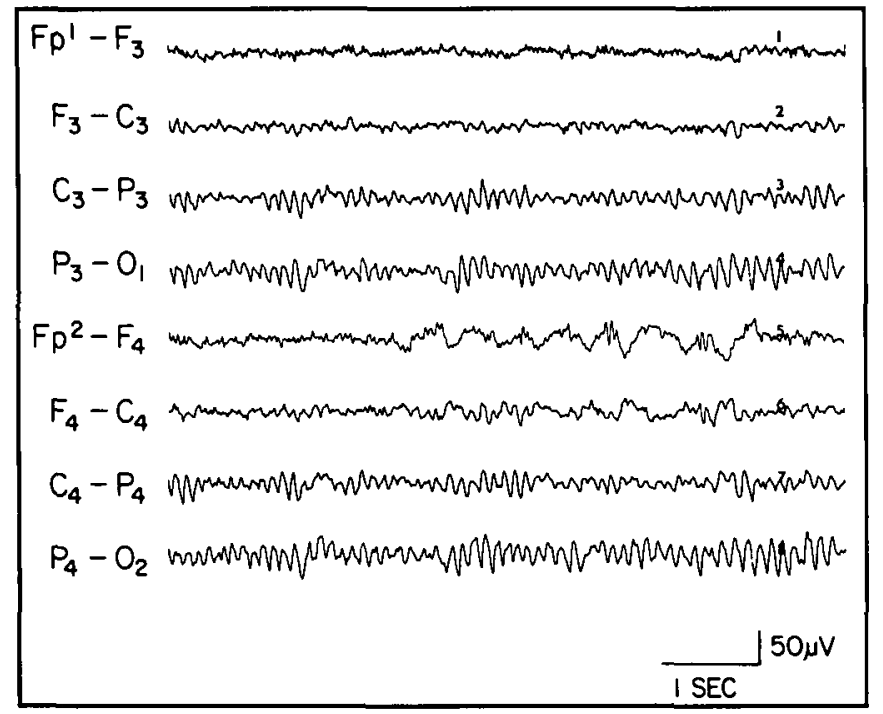

Figure I - EEG done during valproic acid therapy shows right frontal spikes and slow waves but is normal elsewhere.

Reversible pseudoatrophy of the brain has not been described in association with valproic acid therapy, or with other anticonvulsants, but such a condition has been documented previously in patients on steroids, and in Cushing's Syndrome, anorexia nervosa, and chronic alcoholism. ${ }^{5,6,7.8 .9}$ That the valproic acid was responsible for the CT findings, in addition to the other side effects, is not proven and can only be implied by the complete immediate resolution of the abnormalities when the drug was discontinued, and the fact that the patient was on no other medication at the time. In addition, there was no clinical evidence of diffuse brain disease such as encephalitis or psychiatric disorder, although extensive investigations were not carried out for these considering the patient's relatively mild symptoms and their onset in relation to the start of valproic acid therapy. Hepatotoxicity was ruled out and similar CT changes have not been identified as being associated with that syndrome.

Valproic acid, particularly when used as monotherapy, has minimal effect on cognition. ${ }^{10}$ However, at least one patient has been reported who, while on valproic acid monotherapy, developed reversible dementia. ${ }^{11}$ In that patient, neuropsychological testing revealed a full scale IQ of 70 on valproic acid compared to 98 and 96 before and after therapy. A single CT scan during drug therapy was said to be normal. The marked apathy and deterioration in school performance which occurred in the patient described herein is therefore unusual and may have been related to the pseudoatrophic process seen by CT. A similar association was noted in some children who developed reversible brain atrophy with "psuedodementia" on steroid therapy. ${ }^{12}$

The explanation for these reversible CT abnormalities is unknown. Drug induced hyperammonemia with normal liver function tests was not ruled out but that syndrome if symptom-
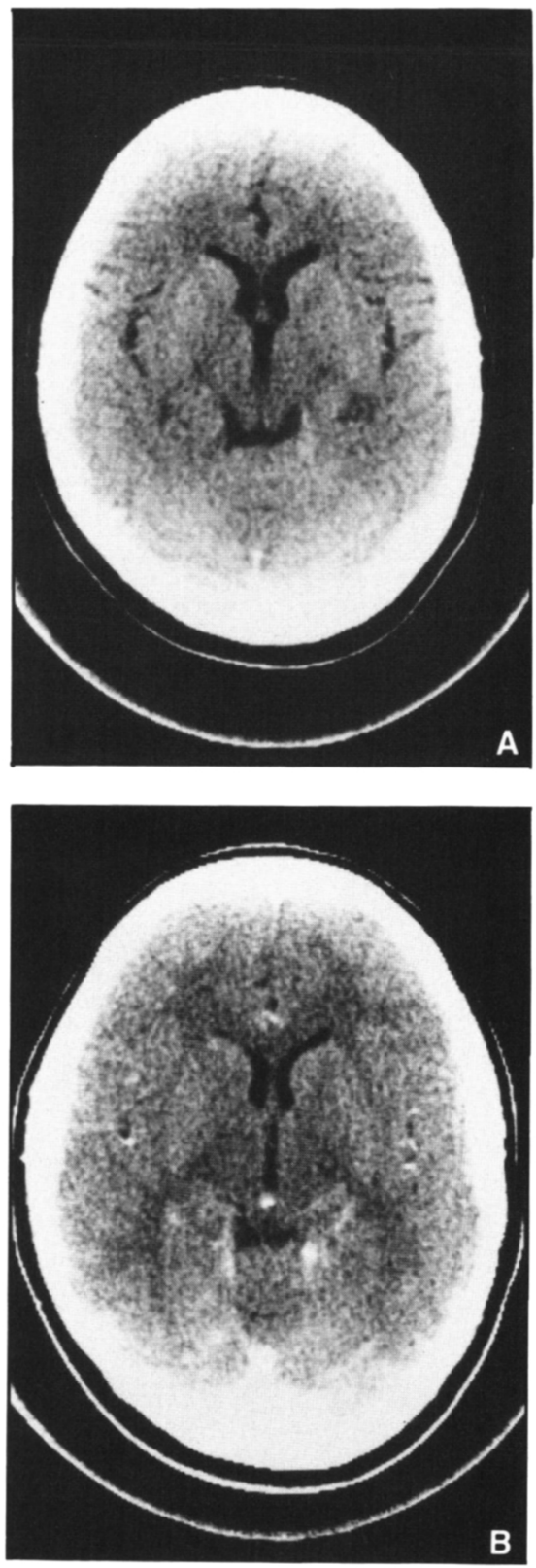

Figure 2(A) - CT scan during therapy with valproic acid shows enlarged ventricles, cisterns, and sulci. (B) - Four months after stopping valproic acid $C T$ scan is normal as was the initial CT before therapy.

atic is associated with drowsiness or stupor, which this patient did not have. Nonetheless, as pointed out by Zaret and Cohen in their patient, it remains a possible pathophysiological mechanism. " The development of a communicating hydrocephalus due to alterations in CSF absorption or excretion is another possibility. ${ }^{8.9}$ This is given some support by the finding of elevated intracranial pressure in two children who developed evidence of brain atrophy on ACTH.${ }^{13}$ Various endocrine abnormalities have been described with valproic acid therapy, including decreases in ACTH and glucocorticoids. ${ }^{14}$ It is conceivable that the reversible atrophy associated with such therapy is related to a disturbance in pituitary-adrenal function, raising the possibility that the brain shrinkage in this patient 
could be due to a similar effect induced by valproic acid. Loss of brain water content, as might occur by some osmotic change across the blood brain barrier or reduction in cerebral blood flow via diffuse vasospasm, could also account for an apparent loss of brain volume. Since none of these abnormalities were specifically tested for in this patient, the cause can only be attributed to an unusual idiosyncratic response to the drug which fortunately was reversible.

\section{ACKNOWLEDGEMENTS}

Dr. McLachlan is a Career Scientist of the Ontario Ministry of Health.

\section{REFERENCES}

1. Dreifuss FE, Santilli, N. Valproic acid hepatic fatalities: Analysis of U.S. cases. Neurology 1986; 36 (Suppl): 175.

2. Fenichel GM, Greene HL. Valproate hepatotoxicity: Two new cases, a summary of others, and recommendations. Pediat Neurol 1985; 1: 109-13.

3. Jeavons PM. Valproate. In: Woodbury DM, Penry JK, Pippenger CE, eds. Antiepileptic Drugs, 2nd edition. Raven Press: New York, 1982: 601-10.
4. Schmidt D. Adverse effects of valproate. Epilepsia 1984;25(Suppl): S44-9.

5. Bentson J, Reza M, Winter et al. Steroids and apparent cerebral atrophy on computed tomography scans. J Comput Assist Tomogr 1978; 2: 16-23.

6. Carlen PL, Wortzman G, Holgate RC et al. Reversible cerebral atrophy in recently abstinent chronic alcoholics measured by computed tomography scans. Science $1978 ; 200$ : 1076-8.

7. Glaze DG, Hrachovy RA, Frost JK et al. Computed tomography in infantile spasms: Effects of hormonal therapy. Pediat Neurol 1986; 2 : 23-7.

8. Heinz ER, Martinez J, Haenggeli A. Reversibility of cerebral atrophy in anorexia nervosa and Cushing's Syndrome. J Comput Assist Tomogr 1977; 1: 415-8.

9. Lyen KR, Holland IM, Lyen YC. Reversible cerebral atrophy in infantile spasms caused by corticotropin. Lancet 1979;2:37-8.

10. Trimble MR, Thompson PJ. Sodium valproate and cognitive function. Epilepsia 1984; 25 (Suppl): S60-4.

11. Zaret BS, Cohen RA. Reversible valproic acid-induced dementia: A case report. Epilepsia 1986; 27: 234-40.

12. Lagenstein I, Willig RP, Kuhne D. Cranial computerized tomography (CCT) findings in children treated with ACTH and dexamethasone: First results. Neuropaediatrie 1979; 10:370-84.

13. Carollo C, Marian G, Scanarini M et al. CT and ACTH treatment in infantile spasms. Child's Brain 1982; 9: 347-53.

14. Kritzler RK, Vining EPG, Plotnick LP. Sodium valproate and corticotropin suppression in the child treated for seizures. J Pediatr 1983; 102: 142-43. 